\title{
携帯型床反カ計およびモーションセンサを用いた歩行解析システムの開発*
}

\author{
足立 渡*1, 辻内 伸好 ${ }^{* 2}$, 小泉 孝之*2 \\ 塩島 康造*3, 土屋 陽太郎 ${ }^{* 4}$ ，井上 喜雄 ${ }^{* 5}$
}

\section{Development of Walking Analysis System Using by Motion Sensor with Mobile Force Plate}

\author{
Wataru ADACHI ${ }^{* 1}$, Nobutaka TSUJIUCHI, Takayuki KOIZUMI, \\ Kouzou SHIOJIMA, Youtaro TSUCHIYA and Yoshio INOUE \\ ${ }^{* 1}$ Doshisha Univ. Dept. of Mechanical Engineering \\ Tatara Miyakodani 1-3, Kyotanabe-City, Kyoto, 610-0321 Japan
}

In walking analysis, which is one useful method for efficient physical rehabilitation, the ground reaction force, the center of pressure and the body orientation data are measured during walking. In the past, these data were measured by a 3D motion analysis system consisting of high-speed cameras and force plates, which must be installed in the floor. However, a conventional 3D motion analysis system can measure the ground reaction force and the center of pressure just on force plates during a few steps. In addition, the subjects' stride lengths are limited because they have to walk on the center of the force plate. These problems can be resolved by converting conventional devices into wearable devices. We used a measuring device consisting of portable force plates and motion sensors. We developed a walking analysis system that calculates the ground reaction force, the center of pressure, and the body orientations and measured a walking subject to estimate this system. We simultaneously used a conventional 3D motion analysis system to compare with our development system and showed its validity for measurements of ground reaction force, the center of pressure and posture of lower limb.

Key Words : Wearable Sensor, Force Plate, Motion Analysis, Ground Reaction Force, Center of Pressure, Stick Picture

\section{1. 緒言}

脳卒中のような疾病に起因する歩行障害に対するリハビリテーションは重要である ${ }^{(1)(2)}$. 患者に対するリハビリ テーション中に, 理学療法士らが下肢の関節モーメントの情報を把握することは，指示を与える上でとても有益 である(3)(4). 従来, 下肢の関節モーメントは高速度カメラと床反力計からなる三次元動作解析装置により得られた データを基に，逆動力学の手法を用いて計算されてきた。しかし，従来の計測装置は実験施設に設置する必要が あり，計測可能な運動の種類や計測範囲などにも制限がある。また，床反力計を数多く設置する場合，広範囲に およぶ実験施設が必要となり，費用も非常に高くなるために実現可能性は非常に低い，さらに，床面に設置され た床反力計の間隔が，必ずしも全ての被験者にとって最適に配置されているとは限らない。このような問題を解 決する方法として，床反力計や三次元動作解析装置をウエアラブルな装置に置き換えることが考えられる. これ までの動作解析において加速度センサ，ジャイロセンサおよび地磁気センサを用いたウエアラブルなモーション センサが用いられたことがあるが，ウエアラブルな床反力計が用いられたことはない．類似した装置として，圧 力分布を計測する事が出来る装置を履物に挿入したものが市販されており，圧力分布の定量的な評価が行われて いる. しかし, 出力と量的精度の時間変化が不十分であるので, フォースプレートとしての精度を維持すること が困難である．加えて，このフォースプレートが計測できるのは垂直方向の力のみである.

* 原稿受付 2011 年 10 月 21 日

*1 正員, 同志社大学（广610-0321 京都府京田辺市多々羅都谷 1-3)

*2 正員, フェロー, 同志社大学（三610-0321 京都府京田辺市多々羅都谷 1-3）

*3 (株)テック技販（广611-0033 京都府宇治市大久保町西ノ端 1-22）

$*_{4}$ 正員, (株)テック技販（广611-0033 京都府宇治市大久保町西ノ端 1-22）

*5 正員, フェロー, 高知工科大学 (下782-8502 高知県香美市土佐山田町宮ノ口 185)

E-mail: etk1301@mail4.doshisha.ac.jp 
これらの状況を考慮した上で，「M3Dシステム」と呼ばれるウエアラブルな歩行解析システムが開発された ${ }^{(5)}$. M3Dシステムは小型の携帯型床反力計や加速度センサ, ジャイロセンサおよび地磁気センサからなるモーション センサによって構成されている，このM3Dシステムは比較的安価であり，制約条件も少ない．歩行実験において は携帯型床反力計やモーションセンサからの出力を用いて計算することで床反力, 圧力中心の軌跡および下肢の 姿勢を算出することが可能である.

本研究では, M3D システムの妥当性を検証するために, 歩行運動を含む複数条件の運動を対象として計測を行 った. 歩行運動の計測の際には，比較のために M3D システムと同時に既存の三次元動作解析装置を用いた. そ の結果，M3D システムは既存の三次元動作解析装置と同等の性能を有していることが明らかになった.

\section{M3D システム}

\section{$2 \cdot 1$ M3D システムの構成}

M3Dシステムは4つの携帯型床反力計 (M3D-FP) と6つのモーションセンサ (M3D-MS) およびデータトランス ミッタ (M3D-DT) によって構成されている. 図1にM3Dシステムの構成を示す.

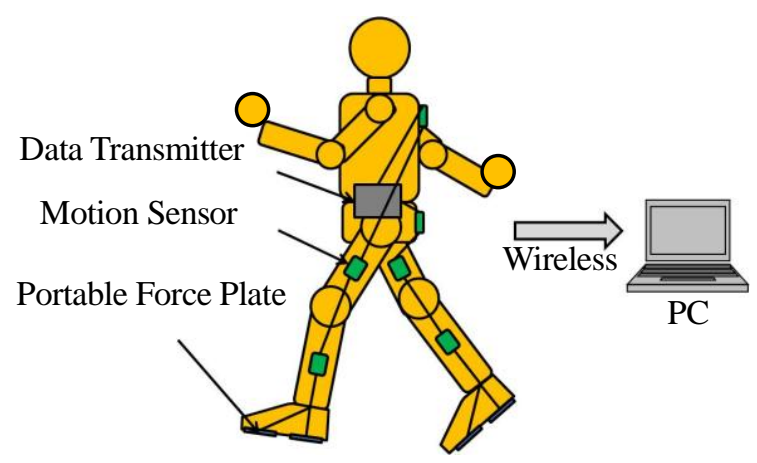

Fig. 1 Constitution of M3D System

次に，床反力計やモーションセンサに内蔵されている各種センサの諸元について表1に示す.

Table 1 Specification of Sensors

\begin{tabular}{cccc}
\hline \hline Sensor & Rated Value & Nonlinearity & Responsive \\
\hline \multirow{2}{*}{ Force } & $\mathrm{XY:} \pm 250[\mathrm{~N}]$, & $\pm 1[\% \mathrm{FS}]$ & $\pm 2[\mathrm{KHz}]$ \\
& $\mathrm{Z:} \pm 500[\mathrm{~N}]$ & & \\
\hline Acceleration & $\pm 19.6\left[\mathrm{~m} / \mathrm{s}^{2}\right]$ & $\pm 0.5[\% \mathrm{FS}]$ & $\pm 2[\mathrm{KHz}]$ \\
\hline Gyro & $\pm 1200[\mathrm{deg} / \mathrm{s}]$ & $\pm 1[\% \mathrm{FS}]$ & $\pm 140[\mathrm{~Hz}]$ \\
\hline Geomagnetism & $\pm 70000[\mathrm{nT}]$ & $\pm 0.1[\% \mathrm{FS}]$ & $\pm 10[\mathrm{KHz}]$ \\
\hline \hline
\end{tabular}

さらに, システムを構成するコンポーネントの諸元について表2に示す.

Table 2 Specification of M3D Components

\begin{tabular}{cccccc}
\hline \hline Component & Width & Depth & Height & Weight & Rated Value \\
\hline M3D-FP & $88[\mathrm{~mm}]$ & $82[\mathrm{~mm}]$ & $6[\mathrm{~mm}]$ & $135[\mathrm{~g}]$ & $\begin{array}{c}\text { Fx, Fy: } \pm 500[\mathrm{~N}] \mathrm{Fz}: \pm 1000[\mathrm{~N}] \\
\text { Mx, My: } \pm 15[\mathrm{~N} \cdot \mathrm{m}] \mathrm{Mz}: \pm 30[\mathrm{~N} \cdot \mathrm{m}]\end{array}$ \\
\hline M3D-MS & $35[\mathrm{~mm}]$ & $50[\mathrm{~mm}]$ & $10.5[\mathrm{~mm}]$ & $16.5[\mathrm{~g}]$ & \\
\hline M3D-DT & $145[\mathrm{~mm}]$ & $100[\mathrm{~mm}]$ & $40[\mathrm{~mm}]$ & $565[\mathrm{~g}]$ & \\
\hline \hline
\end{tabular}

表2より，M3Dシステムに用いられる携帯型床反力計やモーションセンサ等は小型・計量であることが明らかで ある. M3Dシステムはウエアラブルな計測装置であるから, 被験者が受ける負荷を小さくすることは非常に重要 である. 
ここでM3D-MS，M3D-FPおよびM3D-DTの特徵について説明する．まず，M3D-MSは図2(a)に示すような形状で あり3軸加速度センサが1個，3軸ジヤイロセンサが1個，3軸地磁気センサが1個内蔵されている．M3D-MSは運動 計測の際に6個用いられ, 図1に示寸ような箇所に貼付されることで, 下肢および体幹の運動学データを計測する. 次に，M3D-FPは図2(b)に示すように3個の3軸力覚センサが内蔵されている．M3D-FPは専用シューズの底面に両 面テープを用いて取り付ける．なお，片足につき2枚のM3D-FPを用いる．さらに，M3D-FPにはM3D-MS と同様 の加速度センサ, ジャイロセンサおよび地磁気センサが内蔵されているので, 足部の運動学データを計測する事 が可能である．以上のようなM3D-MSおよびM3D-FPにより得られる計測データは，図2(c)に示すM3D-DTを介し て無線でPCへ転送され，記録される，本研究では，M3D-MSおよびM3D-FPを用いて計測されたデータを用いて 床反力, 圧力中心および下肢の姿勢を算出した.

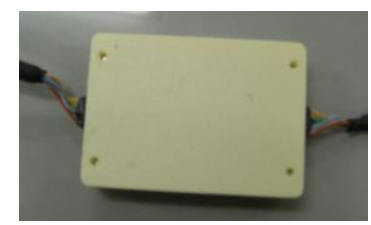

(a) Motion Sensor (M3D-MS)

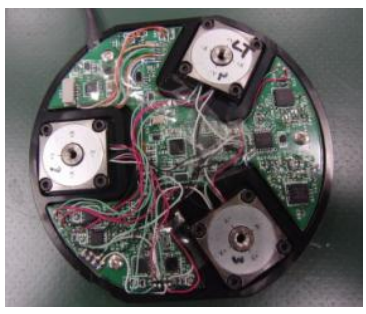

(b) Portable Force Plate (M3D-FP)

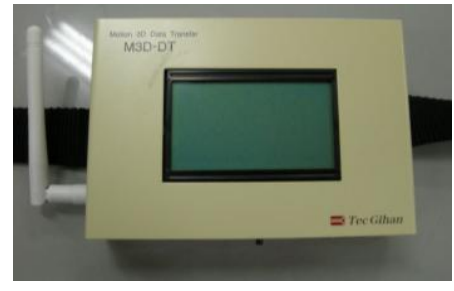

(c) Data Transmitter (M3D-DT)

Fig. 2 M3D System Components

\section{$2 \cdot 2$ 座標系の定義}

今後，左上への添え字として書かれる「S」はセンサ座標系を意味し，同様の「G」は固定座標系を意味する. また，どちらの座標系も右手座標系であり，各軸に関して時計回りを正の方向とする.

ここで，M3D-FPのセンサ座標系 $\left({ }^{S} X,{ }^{S} Y\right.$ おび $\left.Z\right)$ を図3のように定義した．さらに，片足につきM3D-FPを2 枚使用することで1枚の床反力計としてのセンサ出力を得るので, 図4に示すように, 片足全体のセンサ座標系の 原点は踵側のM3D-FPのセンサ座標系の原点と同一であると定義した.
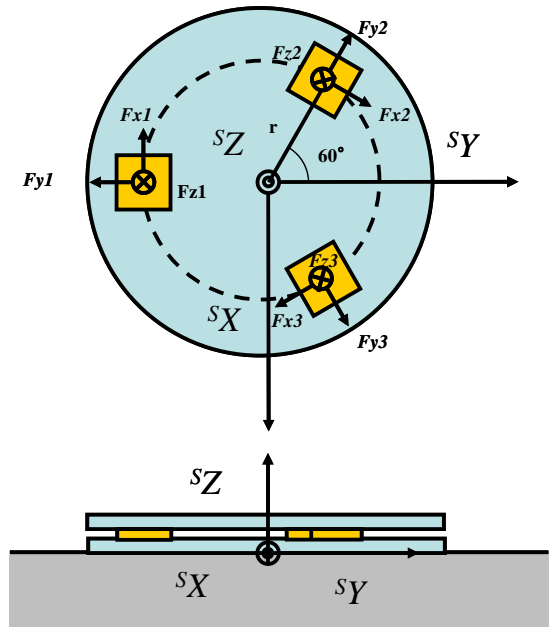

Fig. 3 Sensor Coordinate System of a M3D-FP

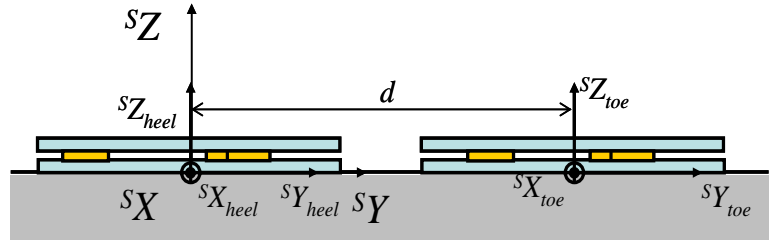

Fig. 4 Definition of Total Force coordinate system

M3D-FPにおけるセンサ座標系 ${ }^{S} X,{ }^{S} Y,{ }^{s} Z$ を図3に示すように定義すると, センサ座標系各軸方向にかかる床反 力 $^{S} \mathbf{F}\left(=\left[\begin{array}{lll}{ }^{S} F X & { }^{S} F Y & { }^{S} F Z\end{array}{ }^{T}\right):[\mathrm{N}]\right.$ は3軸力覚センサ出力 $F x j, F y j, F z j,(\mathrm{j}=1,2,3):[\mathrm{N}]$ を用いて次式で算出するこ とが可能である(6)(7).

$$
{ }^{S} \mathbf{F}=\left[\begin{array}{l}
{ }^{S} F X \\
{ }^{S} F Y \\
{ }^{S} F Z
\end{array}\right]=\left[\begin{array}{l}
F x 1-(F x 2+F x 3) \sin 30^{\circ}+(F y 2-F y 3) \cos 30^{\circ} \\
F y 1-(F y 2+F y 3) \sin 30^{\circ}+(F x 3-F x 2) \cos 30^{\circ} \\
F z 1+F z 2+F z 3
\end{array}\right]
$$


また，M3D-FPが地面より受ける3軸まわりのモーメント ${ }^{S} \mathbf{M}\left(=\left[\begin{array}{llll}{ }^{S} M X & { }^{S} M Y & { }^{S} M Z\end{array}\right]^{T}\right):[\mathrm{N} \cdot \mathrm{m}]$ は3軸力覚センサ 出力より次式のように推定することができる.

$$
{ }^{s} \mathbf{M}=\left[\begin{array}{l}
{ }^{s} M X \\
{ }^{s} M Y \\
{ }^{s} M Z
\end{array}\right]=\left[\begin{array}{l}
-r F z 1+r(F z 2+F z 3) \sin 30^{\circ} \\
r(F z 2-F z 3) \cos 30^{\circ} \\
r(F x 1+F x 2+F x 3)
\end{array}\right]
$$

ここで, $r$ は原点と3軸力覚センサ中心の距離であり $0.03[\mathrm{~m}]$ である. 以上より求めた床反力およびモーメントよ り，センサ座標系における圧力中心座標 : ${ }^{S} \mathbf{C o p}\left(=\left[\begin{array}{lll}{ }^{S} \operatorname{Cop} X & { }^{S} \operatorname{Cop} Y & { }^{S} \operatorname{Cop} Z\end{array}\right]^{T}\right) ：[\mathrm{~m}]$ は次式で算出することが可 能である.

$$
{ }^{S} \mathbf{C o p}=\left[\begin{array}{l}
{ }^{S}{ }_{C o p X} \\
{ }^{S} \operatorname{Cop} Y \\
{ }^{S} \operatorname{CopZ}
\end{array}\right]=\left[\begin{array}{l}
-{ }^{S} M Y /{ }^{S} F Z \\
{ }^{S} M X /{ }^{S} F Z \\
0
\end{array}\right]
$$

図4のように，通常M3D-FPは片足に2枚ずつ使用する，つま先側のM3D-FP出力を添字のtoe，踵側のM3D-FP出力 を添字のheelで表す，図4のように，片足全体のセンサ座標系の原点は踵側M3D-FPのセンサ座標系の原点と同一

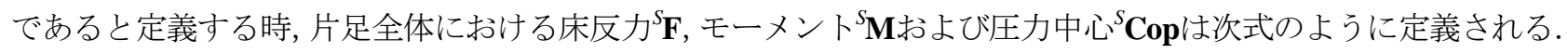

$$
\begin{gathered}
{ }^{S} \mathbf{F}=\left[\begin{array}{c}
{ }^{S} F X_{\text {toe }}+{ }^{S} F X_{\text {heel }} \\
{ }^{S} F Y_{\text {toe }}+{ }^{S} F Y_{\text {heel }} \\
{ }^{S} Z_{\text {toe }}+{ }^{S} F Z_{\text {heel }}
\end{array}\right] \\
{ }^{S} \mathbf{M}=\left[\begin{array}{c}
{ }^{S} M X_{\text {toe }}+{ }^{S} M X_{\text {heel }}+{ }^{S} F Z_{\text {toe }} d \\
{ }^{S} M Y_{\text {toe }}+{ }^{S} M Y_{\text {heel }} \\
{ }^{S} M Z_{\text {toe }}+{ }^{S} M Z_{\text {heel }}+{ }^{S} F X_{\text {toe }} d
\end{array}\right] \\
{ }^{S} \mathbf{C o p}=\left[\begin{array}{c}
-{ }^{S} M Y /{ }^{S} F Z \\
{ }^{S} M X /{ }^{S} F Z \\
0
\end{array}\right]
\end{gathered}
$$

ここで, $d:[\mathrm{m}]$ は 2 枚の M3D-FP の中心間距離である.

\section{$2 \cdot 3$ 下肢の姿勢}

股関節, 膝, 踝, $\mathrm{M} 3 \mathrm{D}-\mathrm{FP}$ 中心の位置座標を $\mathbf{O}\left(=\left[\begin{array}{lll}O_{X} & O_{Y} & O_{Z}\end{array}\right]^{T}\right)$, 関節間ベクトルを $\mathbf{L}\left(=\left[\begin{array}{lll}L_{X} & L_{Y} & L_{Z}\end{array}\right]^{T}\right)$ と すると，M3D システムを装着した時の下肢モデルを図 5 に示す.

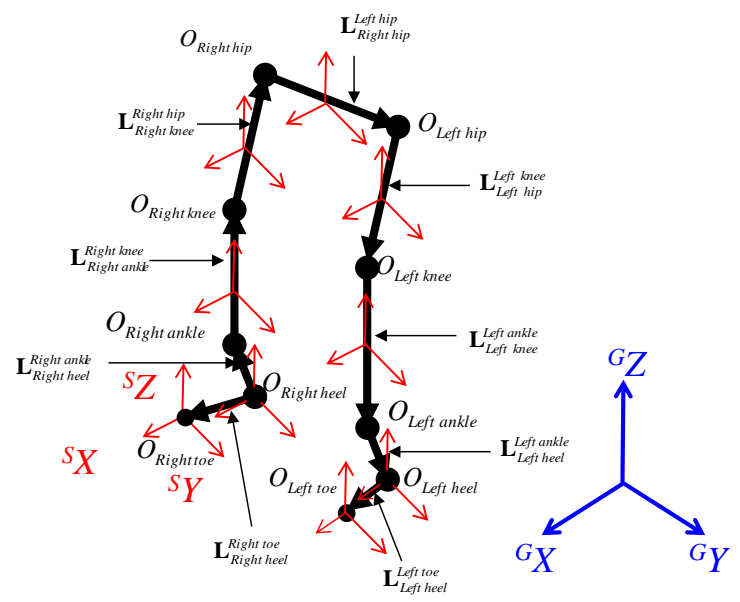

Fig. 5 Lower Leg Model with M3D System 
この下肢モデルは以下のような仮定に基づいている．この仮定は下肢姿勢を算出するためのものである．まず， 歩行中は必ず 4 枚の M3D-FP のいずれかで立脚していて, 立脚点とみなす M3D-FP の中心座標は変化しないとみ な寸.なお, 実際には4 枚の M3D-FP のうち最も大きな床反力を計測している M3D-FP を立脚点であるとみなし, 下肢モデルを計算する. また, 関節間ベクトル $\mathbf{L}$ の大さは変化せず, 各センサが脚部に固定されているので, $\mathbf{L}$ は $S$ 座標系とともに回転する. この時, 固定座標系に対する各センサ座標系の回転を求めることで, 立脚点か ら順に関節座標を算出寸ることが可能である. ジャイロセンサによって計測された角速度を $\boldsymbol{\omega}\left(=\left[\begin{array}{ll}\omega_{X} & \omega_{Y}\end{array}\right.\right.$ $\left.\left.\omega_{Z}\right]^{T}\right):[\mathrm{rad} / \mathrm{s}]$, サンプリング周期を $\Delta t:[\mathrm{s}]$ と置く時, サンプル $i, i-1$ 間の角度変化量 $\boldsymbol{\Delta \boldsymbol { \theta }}\left(=\left[\begin{array}{lll}\Delta \theta_{X} & \Delta \theta_{Y} & \Delta \theta_{Z}\end{array}\right]^{T}\right)$ は 次式で表される.

$$
\boldsymbol{\Delta} \boldsymbol{\theta}=\left[\begin{array}{c}
\Delta \theta_{X} \\
\Delta \theta_{Y} \\
\Delta \theta_{Z}
\end{array}\right]=\left[\begin{array}{c}
\left(\omega_{X_{i}}+\omega_{X_{i-1}}\right) \Delta t / 2 \\
\left(\omega_{Y i}+\omega_{Y i-1}\right) \Delta t / 2 \\
\left(\omega_{Z i}+\omega_{Z i-1}\right) \Delta t / 2
\end{array}\right]
$$

また，サンプル $i-1$ に対するサンプル $i$ の各軸周りの回転行列 $\mathbf{R}_{\mathbf{x}}, \mathbf{R}_{\mathbf{y}}, \mathbf{R}_{\mathbf{z}}$ は,

$$
\mathbf{R}_{\mathbf{X}_{i-1}^{i}}^{i}=\left[\begin{array}{ccc}
1 & 0 & 0 \\
0 & \cos \Delta \theta_{X} & -\sin \Delta \theta_{X} \\
0 & \sin \Delta \theta_{X} & \cos \Delta \theta_{X}
\end{array}\right], \quad \mathbf{R}_{\mathbf{Y}_{i-1}^{i}}^{i}=\left[\begin{array}{ccc}
\cos \Delta \theta_{Y} & 0 & \sin \Delta \theta_{Y} \\
0 & 1 & 0 \\
-\sin \Delta \theta_{Y} & 0 & \cos \Delta \theta_{Y}
\end{array}\right], \quad \mathbf{R}_{\mathbf{Z}_{i-1}^{i}}^{i}=\left[\begin{array}{ccc}
\cos \Delta \theta_{Z} & -\sin \Delta \theta_{Z} & 0 \\
\sin \Delta \theta_{Z} & \cos \Delta \theta_{Z} & 0 \\
0 & 0 & 1
\end{array}\right]
$$

であるから，各軸周りの回転行列を合成すると次式のようになる.

$$
\mathbf{R}_{i-1}^{i}=\mathbf{R}_{\mathbf{X}_{i-1}^{i}}^{i} \mathbf{R}_{\mathbf{Y}_{i-1}^{i}}^{i} \mathbf{R}_{\mathbf{Z}_{i-1}^{i}}^{i}
$$

よって，固定座標系に対する回転行列 $\mathbf{R}$ は

$$
\mathbf{R}=\mathbf{E}_{0} \mathbf{R}_{0}^{1} \mathbf{R}_{1}^{2} \ldots \mathbf{R}_{i-1}^{i}
$$

で表される．ここで $\mathbf{E}_{0}$ は固定座標系に対するセンサの初期姿勢行列である.

例として, 右踵で立脚している時について取り扱う。任意サンプル $i$ における各関節の座標は下肢モデルを用い て以下の式で表すことができる.

$$
\begin{aligned}
& \left.{ }^{G} \mathbf{O}_{\text {Right heel }}\right|_{i}=\left[\begin{array}{lll}
{ }^{G} O_{X} \text { Right heel } & \left.{ }_{i-1}^{G} O_{Y_{\text {Right heel }}}\right|_{i-1} & 0
\end{array}\right]^{T} \\
& \left.{ }^{G} \mathbf{O}_{\text {Right toe }}\right|_{i}=\left.{ }^{G} \mathbf{O}_{\text {Right toe }}\right|_{i}+\mathbf{R}_{\text {Right toe }}{ }^{S} \mathbf{L}_{\text {Right heel }}^{\text {Right }} \\
& \left.{ }^{G} \mathbf{O}_{\text {Right ankle }}\right|_{i}=\left.{ }^{G} \mathbf{O}_{\text {Right heel }}\right|_{i}+\mathbf{R}_{\text {Right heel }}{ }^{s} \mathbf{L}_{\text {Right heel }}^{\text {Right ankle }} \\
& \left.{ }^{G} \mathbf{O}_{\text {Right knee }}\right|_{i}=\left.{ }^{G} \mathbf{O}_{\text {Right ankle }}\right|_{i}+\mathbf{R}_{\text {Right lowleg }}{ }^{S} \mathbf{L}_{\text {Right ankle }}^{\text {Right }} \\
& \left.{ }^{G} \mathbf{O}_{\text {Right hip }}\right|_{i}=\left.{ }^{G} \mathbf{O}_{\text {Right knee }}\right|_{i}+\mathbf{R}_{\text {Right upleg }}{ }^{s} \mathbf{L}_{\text {Right knee }}^{\text {Right hip }} \\
& \left.{ }^{G} \mathbf{O}_{\text {Left hip }}\right|_{i}=\left.{ }^{G} \mathbf{O}_{\text {Right hip }}\right|_{i}+\mathbf{R}_{\text {hip }}{ }^{s} \mathbf{L}_{\text {Right hip }}^{\text {Left hip }} \\
& \left.{ }^{G} \mathbf{O}_{\text {Left knee }}\right|_{i}=\left.{ }^{G} \mathbf{O}_{\text {Left hip }}\right|_{i}+\mathbf{R}_{\text {Left upleg }}{ }^{s} \mathbf{L}_{\text {Left hip }}^{\text {Left }} \\
& \left.{ }^{G} \mathbf{O}_{\text {Left ankle }}\right|_{i}=\left.{ }^{G} \mathbf{O}_{\text {Left knee }}\right|_{i}+\mathbf{R}_{\text {Left lowleg }}{ }^{s} \mathbf{L}_{\text {Left knee }}^{\text {Left ankle }} \\
& \left.{ }^{G} \mathbf{O}_{\text {Left heel }}\right|_{i}=\left.{ }^{G} \mathbf{O}_{\text {Left ankle }}\right|_{i}+\mathbf{R}_{\text {Left heel }}{ }^{s} \mathbf{L}_{\text {Left ankle }}^{\text {Left hel }} \\
& \left.{ }^{G} \mathbf{O}_{\text {Left toe }}\right|_{i}=\left.{ }^{G} \mathbf{O}_{\text {Left heel }}\right|_{i}+\mathbf{R}_{\text {Left toe }}{ }^{s} \mathbf{L}_{\text {Left heel }}^{\text {Left }}
\end{aligned}
$$

ここで| ${ }_{i}$ は任意サンプルにおけるパラメータであることを示している.このようにして求めた各点を結ぶことに よって，下肢姿勢をスティックピクチャの形で把握することが出来る. 


\section{3. 実験}

\section{$3 \cdot 1$ 計測装置の構成}

M3Dシステムを評価するために，2種類の実験を行った．実験の際にはM3Dシステムとの比較のために，既存 の三次元動作解析装置 (MAC 3Dシステム) を同時に用いて運動計測を行った. この三次元動作解析装置は赤外線 カメラ (Eagle Digital Camera: Motion Analysis社) 10台と床反力計 (BP400600: AMTI社) 2枚で構成され, 動作解析用 の実験施設に設置されているものである. 実験ではM3Dシステムおよび三次元動作解析装置の同期を取った．本 研究における実験系の構成を図6に示す．なお，計測のサンプリングレートは500 [Hz] とした.

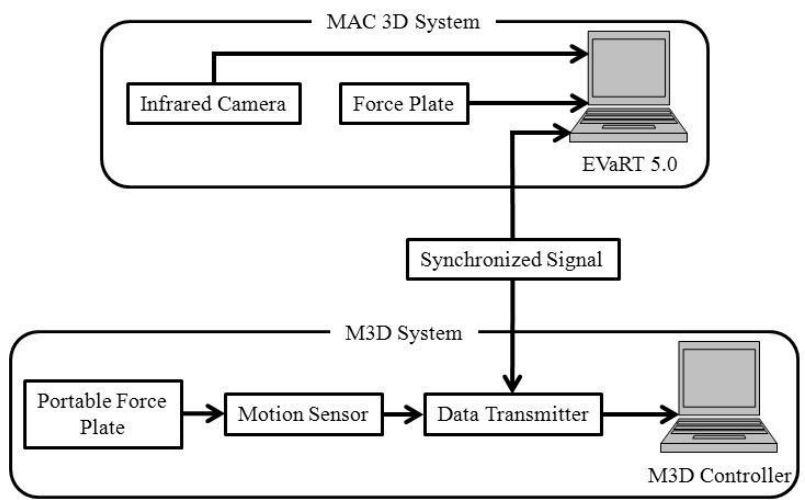

Fig. 6 Composition of Measurement Instruments

\section{$3 \cdot 2$ 実験条件}

実験では，健康な成人男性 1 名 (23 歳，体重 $62[\mathrm{~kg}]$ ，身長 $170[\mathrm{~cm}])$ が M3D システムを装着した上で，下記 のような 2 種類の実験を行った。それぞれの実験の様子を図 7 に示す.

実験 1 : 準静的荷重 (両足を設置型床反力計の上に載せたまま身体を摇らす) (図 7(a))

実験 2 : 直線歩行 (設置型床反力計を踏むようにして直線歩行を行う) (図 7(b))

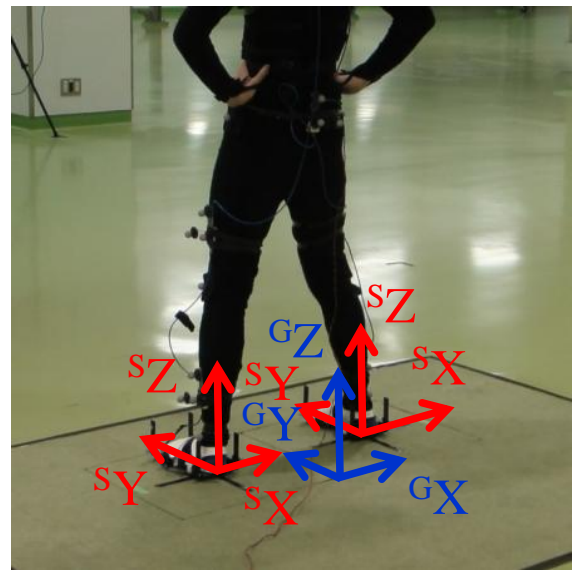

(a) Quasi-static Load Addition

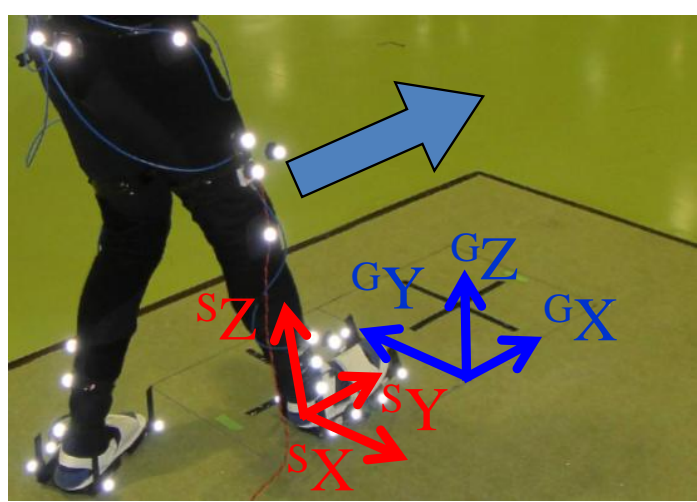

(b) Walking Straight

Fig. 7 Conditions

\section{4. 実験結果}

\section{$4 \cdot 1$ 床反力}

比較検証のために床反力の結果を固定座標系で表現するので，M3D-FPによって計測された床反力データをセ ンサ座標系から固定座標系へ座標変換する必要がある。この座標変換の式は次式のように表される. 


$$
\left(\begin{array}{l}
{ }^{G} F X \\
{ }^{G} F Y \\
{ }^{G} F Z
\end{array}\right)=\mathbf{E}_{\mathbf{Z}_{\text {toe }}}\left(\begin{array}{l}
{ }^{S} F X_{\text {toe }} \\
{ }^{S} F Y_{\text {toe }} \\
{ }^{S} F Z_{\text {toe }}
\end{array}\right)+\mathbf{E}_{\mathbf{Z}_{\text {heel }}}\left(\begin{array}{l}
{ }^{S} F X_{\text {heel }} \\
{ }^{S} F Y_{\text {heel }} \\
{ }^{S} F Z_{\text {heel }}
\end{array}\right)
$$

ここで, 回転行列 $\mathbf{E}_{\mathbf{Z}}$ はM3D-FPに取り付けられた赤外線反射マーカーの座標位置により次式のように算出される.

$$
\mathbf{E}_{\mathbf{Z}}=\left[\begin{array}{ccc}
\cos ^{G} \theta_{Z} & -\sin ^{G} \theta_{Z} & 0 \\
\sin ^{G} \theta_{Z} & \cos ^{G} \theta_{Z} & 0 \\
0 & 0 & 1
\end{array}\right]
$$

固定座標系で表された床反力のうち右足についての結果を，図8に実験条件別に示すＭ3Dシステムにより測定 された床反力と既存の三次元動作解析装置により測定された床反力との誤差は，6.4\%以下であった.

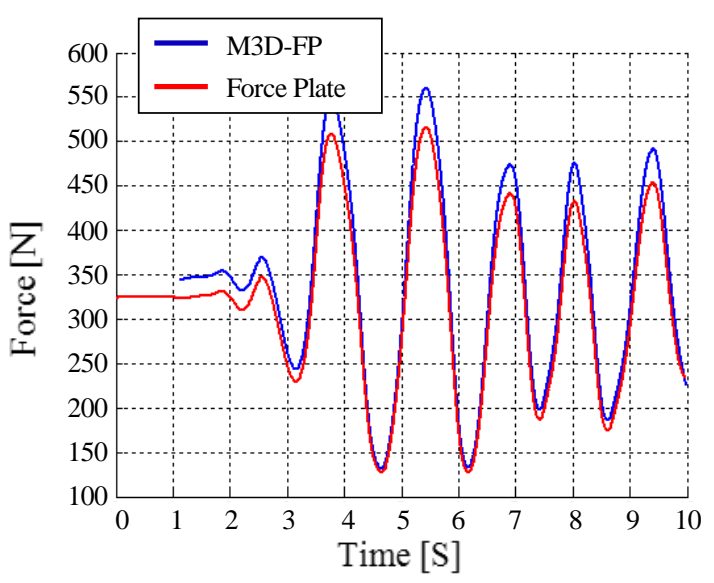

(a) Quasi-static Load Addition

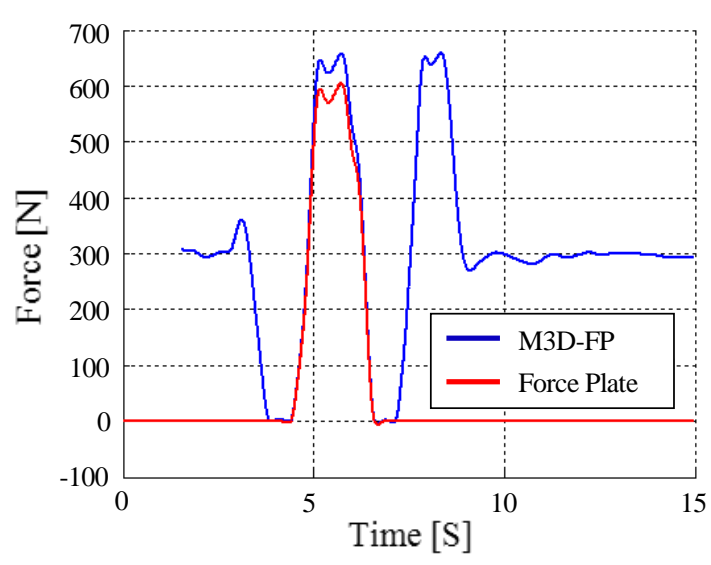

(b) Walking Straight

Fig. 8 Ground Reaction Force: Right Foot

\section{4 - 2 圧力中心}

床反力と同様にして, M3Dシステムおよび既存の三次元動作解析装置の双方の計測データを用いて算出した圧 力中心の結果を図9に示す.この時，双方の圧力中心の誤差は4.7\%以下であった.

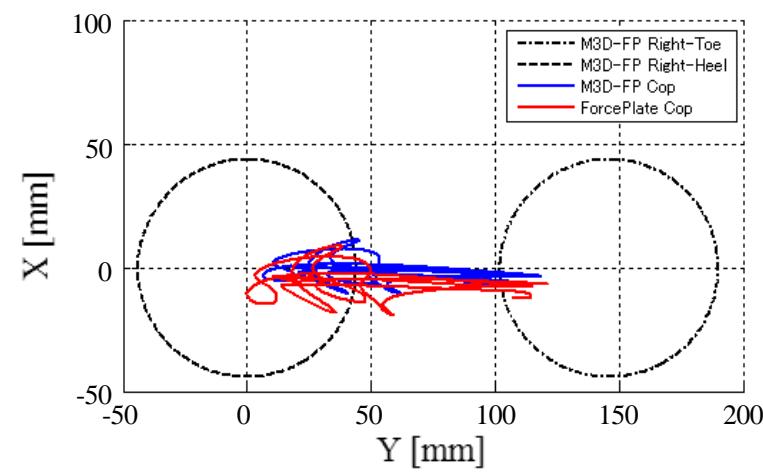

(a) Quasi-static Load Addition

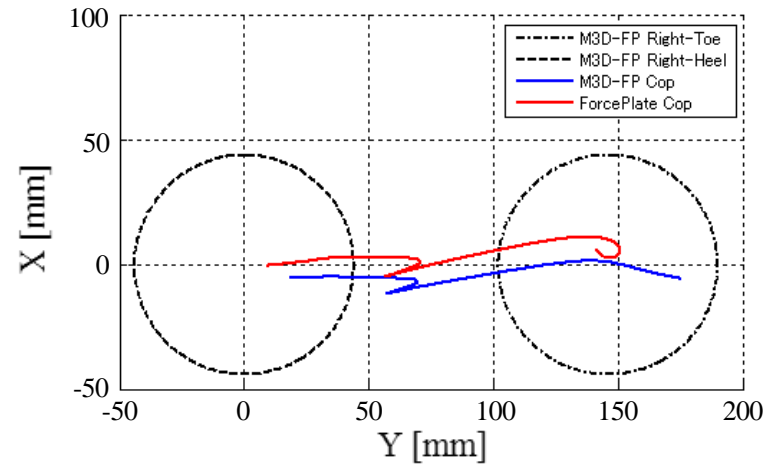

(b) Walking Straight

Fig. 9 Center of Pressure: Right Foot

\section{$4 \cdot 3$ 下肢の姿勢}

直線歩行 (実験 2) の際に M3D システムにより得られたデータを用いて算出した下肢の軌跡を，図 10 のよう にスティックピクチャの形で示す. 図 10 より，M3D システムを用いると歩行中の下肢の姿勢をよく計測できる ことが明らかになった。 


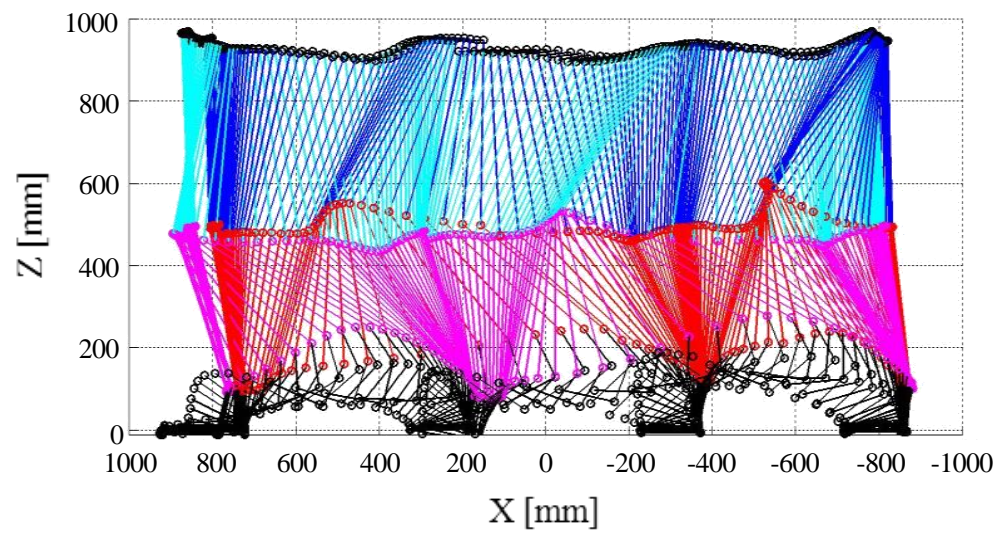

Fig. 10 Stick Picture in Walking Straight: Exp. 2

\section{5. 誤差の補正}

\section{$5 \cdot 1$ 床反力の精度向上}

床反力の計測誤差の原因として，M3D-FP を足部に取り付ける際の取り付け誤差および M3D-FP に内蔵されて いる 3 軸力覚センサの取り付け誤差が考えられる. そこで, これらの誤差を考慮すると, 真の床反力 F と M3D-FP により測定される床反力との関係は次式のように表される.

$$
\mathbf{F}=\left[\begin{array}{c}
F X \\
F Y \\
F Z
\end{array}\right]=\left[\begin{array}{c}
A_{X}\left(B_{X_{\text {toe }}}{ }^{S} F X_{\text {toe }}+B_{X_{\text {heel }}}{ }^{S} F X_{\text {heel }}\right) \\
A_{Y}\left(B_{X_{\text {toe }}}{ }^{S} F Y_{\text {toe }}+B_{X_{\text {heel }}}{ }^{S} F Y_{\text {heel }}\right) \\
A_{Z}\left(B_{X_{\text {toe }}}{ }^{S} F Z_{\text {toe }}+B_{X_{\text {heel }}}{ }^{S} F Z_{\text {heel }}\right)
\end{array}\right]
$$

ここで，A は M3D-FP の取り付け誤差に対する補正係数であり，B は M3D-FP に内蔵される 3 軸力覚センサの取 り付け誤差に対寸る補正係数である。これらの誤差を考慮しなければ，床反力の大きさに比例して誤差が大きく なる. 床反力の算出において垂直成分である $F Z$ の值が最も大きく, さらに，FZについては座標変換を行ってい ないため, $F Z$ に関する補正係数 $A_{Z}$ は簡易的に算出することが可能である. この補正係数 $A_{Z}$ は, 実験 1 の結果を 用いることで次式により算出される.

$$
A_{z}=\frac{1}{N}\left(\sum_{N} \frac{{ }^{G} F Z}{{ }^{S} F Z}\right)
$$

(15)式により算出された補正係数 $A_{Z}$ を(14)式に代入することで，実験 2 における床反力のうち，垂直成分である $F Z$ に関する補正を行った，補正された床反力の結果を図 11 に示寸. 補正の結果, 床反力の垂直成分に関寸る誤 差は $1.3 \%$ 以下に減少した.

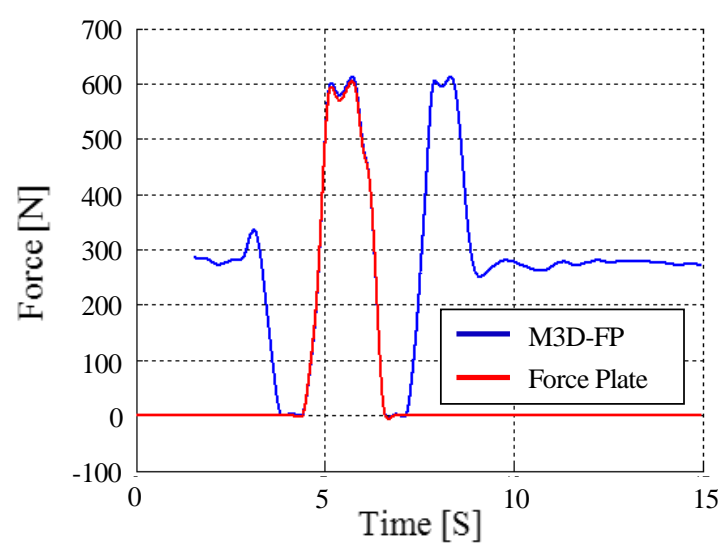

Fig. 11 Corrected Ground Reaction Force: Exp. 2 


\section{$5 \cdot 2$ 圧カ中心の精度向上}

図 9 に示すように，圧力中心の軌跡はよく一致している. しかし，M3D-FP の中心座標のオフセットによる一 様なずれが全体に生じている，そこで，M3D-FP の中心座標のオフセットを考慮した上で算出される，設置型床 反力計による圧力中心座標は次式のように表される．なお，次式は右足に関する圧力中心を求めている.

$$
{ }^{S} \mathbf{C o p}_{F P}=\mathbf{E}_{\mathbf{Z}_{\text {Right heel }}}{ }^{-1}\left\{{ }^{G} \mathbf{C o p}_{F P}{ }^{G}{ }^{G} \mathbf{O}_{\text {Right heel }}\right\}-\overline{\mathbf{e} \_ \text {Cop }}
$$

ここで, ${ }^{\mathrm{G}} \mathbf{O}_{\text {Rightheel }}$ は右踵の座標位置であり， $\mathbf{\text { e_Cop}}$ は M3D-FP と設置型床反力計の圧力中心の軌跡の差の相加平 均である.

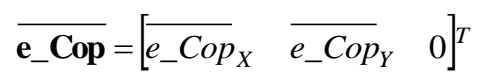

M3D-FP の中心座標のオフセットを考慮し, 圧力中心の誤差を補正した結果を図 12 に示寸. 補正の結果, 圧力中 心に関する誤差は 4.6\%以下に減少した。

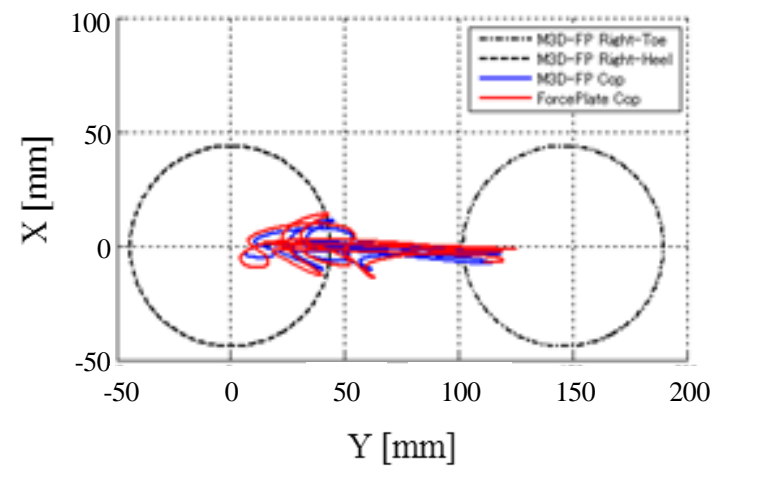

(a) Quasi-static Load Addition

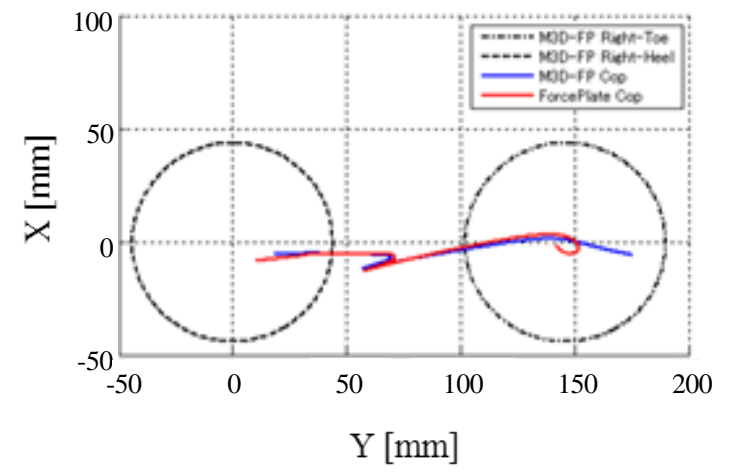

(b) Walking Straight

Fig. 12 Corrected Center of Pressure: Right Foot

\section{6. 結 語}

本研究では, 携帯型床反力計およびモーションセンサからなるM3Dシステムを開発し, 歩行解析装置として用 いた．M3Dシステムの評価のために従来の三次元動作解析装置を同時に用いて，2種類の実験を行った．その結 果，以下のような結論を得た.

1） M3Dシステムは従来の動作解析装置と比較して, 1.3\%以下の誤差で床反力を計測することが可能である.

2) M3Dシステムは従来の動作解析装置と比較して, 4.6\%以下の誤差で圧力中心を計測することが可能である.

3） M3Dシステムを用いることで，歩行中の下肢の姿勢を計測することが出来る.

\section{謝 辞}

なお本研究の一部は, 日本学術振興会科学研究費補助金基盤研究(A) (課題番号 : 23246041) の援助を受けた. 記して謝意を表す.

\section{文献}

(1) M. C. Cramp, R. J. Greenwood, M. Gill, A. Lehmann, J.C. Rothwell, O. M. Scott, "Effectiveness of a community-based low intensity exercise programme for ambulatory stroke survivors," Disability and Rehabilitation, vol.32, №.3 (2010), pp. 239-247.

(2) A. Srivastava, A. B. Taly, A. Gupta, S. Kumar, and T. Murali, "Post-stroke balance training: Role of force platform with visual feedback technique,” Journal of the Neurological Sciences, Vol.287, No.1-2 (2009), pp. 89-93. 
(3) J. Z. Wu, S. S. Chiou, and C.S. Pan, "Analysis of musculoskeletal loadings in lower limbs during stilts walking in occupational activity," Annals of Biomedical Engineering, Vol.37, No.6 (2009), pp. 1177-1189.

(4) Y. C. Lin, J. P. Walter, S. A. Banks, M. G. Pandy, and B. J. Fregly, "Simultaneous prediction of muscle and contact forces in the knee during gait," Journal of Biomechanics, Vol.43, No.5 (2009), pp. 945-952.

(5) T. Liu, Y. Inoue, K. Shibata, Y. Hirota, and K. Shiojima," A Mobile Force Plate System and Its Application to Quantitative Evaluation of Normal and Pathological Gait," 2010 IEEE/ASME International Conference on Advanced Intelligent Mechatronics (AIM), (2010), pp. 272-277.

(6) Peter H. Veltink, Christian Liedtke, Ed Droog, Herman van der Kooij, "Ambulatory Measurement of Ground Reaction Forces," IEEE Transactions on Neural Systems and Rehabilitation Engineering, Vol.13, No. 3 (2005), pp. 423-427.

(7) Peter H. Veltink, H. Martin Schepers, and H. F. J. M. Koopman, "Ambulatory Assessment of Ankle and Foot Dynamics," IEEE Transactions on Biomedical Engineering, Vol.54, No. 5 (2007), pp. 895-902. 